\title{
LabVIEW-based Virtual Vacuum Gauge Controller Using a Thermocouple Sensor
}

\author{
Bezhan Bendeliani ${ }^{1,2}$, Zaal Azmaiparashvili'i , Guram Bokuchava ${ }^{1}$, \\ Guram Dgebuadze ${ }^{1}$, Ioseb Metskhvarishvili ${ }^{1,2}$ \\ ${ }^{1}$ Laboratory of Cryogenic Technique and Technologies \\ Ilia Vekua Sukhumi Institute of Physics and Technology Tbilisi, Georgia \\ ${ }^{2}$ Department of microprocessor and measurement systems \\ Georgian Technical University \\ Tbilisi, Georgia
}

\begin{abstract}
The article presents an innovative virtual vacuum gauge made on the base of the vacuum sensor Duniway DST-531. For receipt and sending a signal from the sensor the block NI6210, while for data processing and visualization the LabVIEW graphical programming environment are used. The virtual vacuum gauge proposed by us for the first time applies an approach, where without a vacuum controller, by using only a thermocouple and a multifunction input/output device, a rather accurate measurement of vacuum in the $\sim 4 \times 10^{2}-4 \times 10^{-1} \mathrm{~Pa}$ range is carried out and fixed in the real time.
\end{abstract}

Keywords-Vacuum sensor, vacuum meter, multifunction I/O device, LabVIEW, virtual device

\section{INTRODUCTION}

For measuring different physical parameters and controlling technological processes, the virtual devices [1-4] made in the LabVIEW graphical programming environment [5-7] are gaining popularity. They make it possible to measure different physical quantities (temperature, pressure, vibration, humidity and so on) without measuring systems, using a multifunctional I/O device and a computer.

Such approaches are important for controlling simultaneously different physical parameters in the real time in different places and in the course of an experiment. For example: upon synthesis of $\mathrm{Hg}$-based superconductors

in the controlled pressure environment, the temperature and pressure need to be at same time controlled [8]; for full-value helium filling in the cryostat, necessary need simultaneously control of the nitrogen temperature and vacuum in it [9]. In the course of operation, the amount of helium should be controlled in the cryostat, using several temperature sensors.

Sensors of different principles of operation are used to measure vacuum: diffused, thermocouple, capacitance, ionizing, induction [10-12]. The most popular type of sensors measuring low and medium vacuum is the thermocouple vacuum sensor that can measure vacuum within the range of $1 \times 10^{2}-1 \times 10^{-1} \mathrm{~Pa}$. Such sensors are cheap and noted for high reliability and accuracy $[13,14]$.

In design, they represent a heater and a thermocouple, placed in a tube. During operation, upon reduction of pressure, the temperature of the heater and correspondingly the thermocouple output voltage increase. The vacuum meter's circuit ensures supply of stable current to the filament and amplification of a weak analogous output signal of the thermocouple, its digitalization and indication.

In spite of high accuracy of the traditional measuring systems, the number of parameters measured in them is limited (usually 1-2 channels). An increase in the number of channels leads to an increase the number of equipment and is, correspondingly uneconomic.

The objective of the presented work is to demonstrate an innovative approach to vacuum measurement and monitoring, where the traditional measuring device is substituted with a virtual software device. The number of measured parameters depends only on the number of channels of the multifunction $\mathrm{I} / \mathrm{O}$ device and is thus economically rather profitable.

The proposed virtual vacuum gauge controller for the first time applies an approach, where without a vacuum controller, by using only a thermocouple and a multifunction data input/output device NI6210, a rather accurate measurement of vacuum is performed and continuously fixed in the real time.

\section{EXPERIMENTS AND DISCUSSION}

The measurement of the weak analogous signal released from sensor thermocouple $(0-10 \mathrm{mv})$ without a controller, might lead to a rather significant error. Inasmuch since the heating element and the thermocouple are located in a tube, their resistance also depends on the pressure and if the current through them is conducted, we can judge on the amount of vacuum according to a change in the withdrawn voltage. At the same time, if the current is sufficiently big, the output signal will be correspondingly important and easy to measure.

For example, in pressure within the range of $\sim 4 \times 10^{2}-$ $4 \times 10^{-1} \mathrm{~Pa}$, as an experiment demonstrated, upon conduct of optimal current (150-160 mA) through the heating element of the thermocouple sensor, a change of the voltage produced by the heating element makes only $15 \mathrm{mV}$, which is not enough for accurate calibration of the virtual vacuum gauge controller. However, upon conduct of current of the same magnitude through the thermocouple, a change in the output voltage within the same pressure range made $\sim 60 \mathrm{mV}$. In this case, the magnitude of the voltage $(\sim 300-400 \mathrm{mV})$ provides proper calibration. 
The functional scheme for calibrating of the virtual device by means of the sensor Duniway DST-531 is given in Fig. 1. The mechanical pump EDWARDS E2M18 is used to produce vacuum, the controller Zhenghua Electronic Instrument ZDF-X-Led with the sensor ZJ- 52T used for measure pressure in the range of $2.5 \times 10^{3}-1 \times 10^{-3} \mathrm{~Pa}$.

To conduct stable current through the thermocouple of the test sensor, the source of supply TP3005DM is used. To limit the current magnitude ( $160 \mathrm{~mA})$, a high-precision resistor (nominal - $100 \mathrm{ohm}$ ) with a cooling system is connected in series. The output signal $(\sim 300 \mathrm{mV})$ is communicated to the multifunctional I/O device - National Instruments device NI6210. The result is displayed on a computer monitor by means of the virtual vacuum gauge controller made in the LabVIEW graphical programming environment.

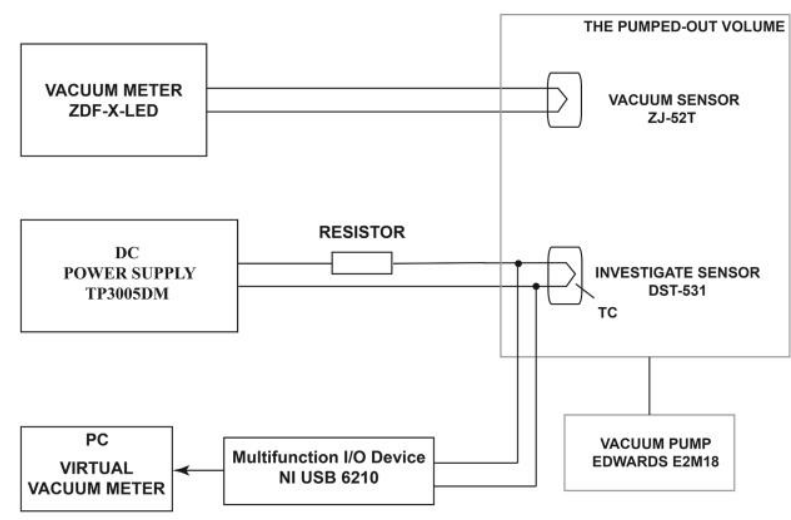

Fig. 1. The functional scheme for calibrating the virtual vacuum gauge
Fig. 2 shows a block scheme of the virtual vacuum gauge controller (VirtVac) program, made in the LabVIEW graphical programming environment.

Initially, the value of the output signal from the thermocouple (V1) is measured upon atmospheric pressure. Thereafter, to increase the measurement accuracy, this value is subtracted from the measured signal (V2).

In addition, to increase the measurement accuracy, the arithmetical mean of the 2000 values measured per second from the sensor thermocouple - block 1 is used. In block 2, the whole range of pressure is divided in two, where the range limits are checked and a appropriate formula is selected. In blocks 3-4, the formulated result is adapted for display on the digital and graphical indicators. Block 5 represents pressure indicators. In block 6, indication of the pressure/time dependence in real time is given. In block 7, the pressure/time dependence is recorded in Excel files. In block 8, the current time and date are formed on the front panel.

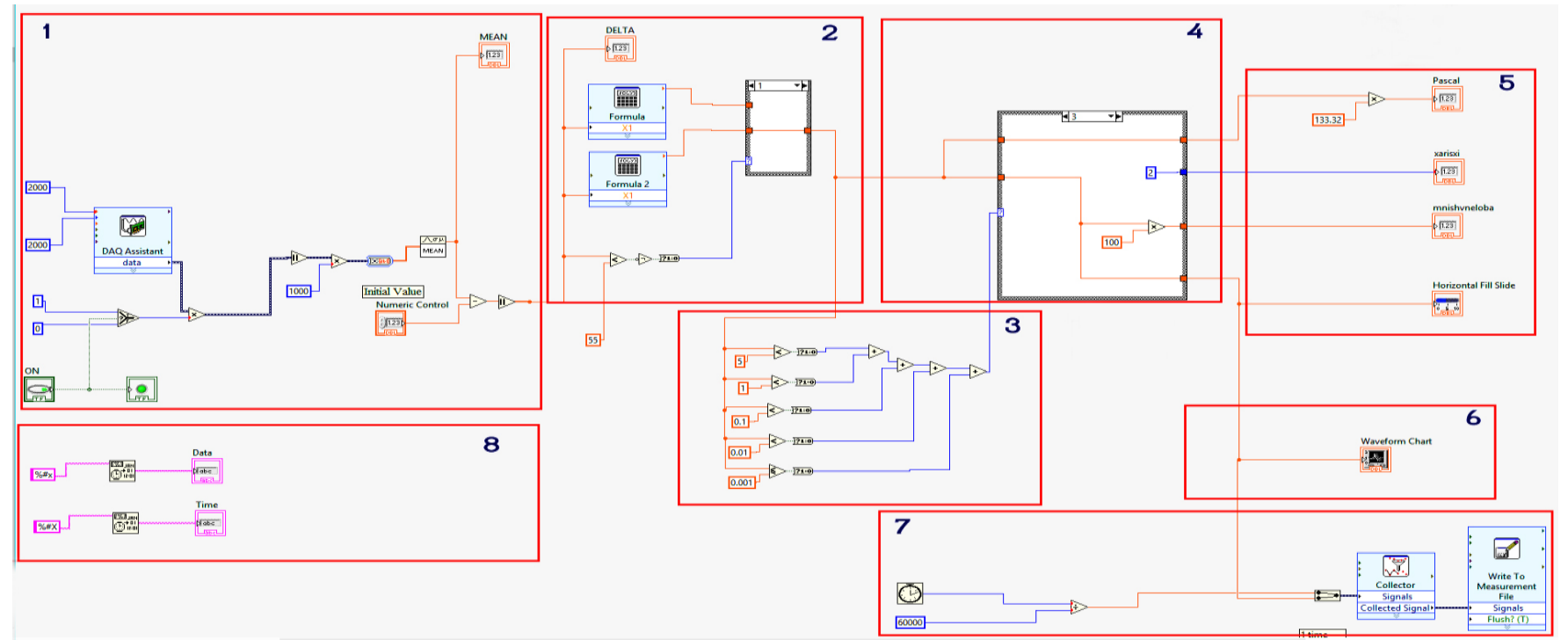

Fig. 2. Block-scheme of the virtual vacuum gauge controller (VirtVac) program made in the LabVIEW 
In figure. 3, presents the pressure dependence $(\mathrm{P})$ on $(\Delta \mathrm{V}=\mathrm{V} 2-\mathrm{V} 1)$, on the basis of which, the program Origin by the linear and polynomial fitting, determines the value of the real pressure. The results are visualized on the front panel of the virtual vacuum gauge controller in the pressure units Pascal and Torr by digital indicators and graphical forms. Digital data also is written to the computer as an Excel file.
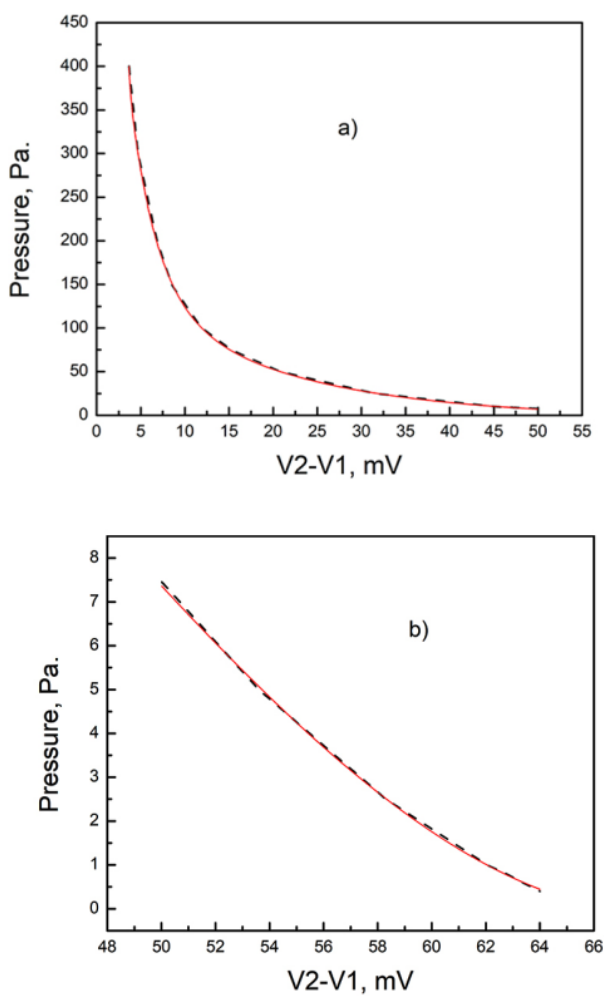

Fig. 3. Derivation of formulas in software package Origin: a) Pressure range $400-7.5 \mathrm{~Pa}$.); b) Pressure range 7.5 - 0.4 Pa. (Dash lines Experimental data, Solid lines - Fitting Data).

Front panel of the VirtVac is shown in Fig. 4.

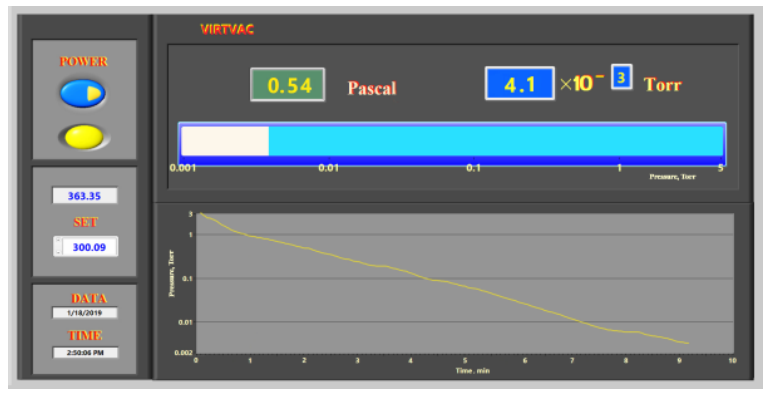

Fig. 4. Front panel of the VirtVac

The first line of Table 1. Indicated the pressure measured in $(\mathrm{Pa})$ by means of the $\mathrm{ZDF}-\mathrm{X}$-Led vacuum gauge meter.

Below given is the assessment of errors of the results for each of the pressures, measured 10 times, by means of standard statistical functions of the Excel program.
Table. 1

Assessment of errors of the results

\begin{tabular}{|c|c|c|c|c|}
\hline Pressure $\mathrm{Pa}$. & 400 & 10 & 1 & 0.4 \\
\hline $\begin{array}{l}\text { Standart } \\
\text { Deviation }\end{array}$ & 4.60 & 0.123 & 0.015 & 0.013 \\
\hline $\begin{array}{l}\text { Sample } \\
\text { Size }\end{array}$ & 10 & 10 & 10 & 10 \\
\hline $\begin{array}{l}\text { Square Root of } \\
\text { the Sample Size }\end{array}$ & 3.16 & 3.16 & 3.16 & 3.16 \\
\hline $\begin{array}{l}\text { Standart Error } \\
\text { of the Mean }\end{array}$ & 1.455 & 0.039 & 0.005 & 0.004 \\
\hline$\%$ & 0.36 & 0.39 & 0.48 & 1.04 \\
\hline \multicolumn{5}{|c|}{ 95\% Confidence Interval } \\
\hline Upper Limit & 401.35 & 10.05 & 1.01 & 0.41 \\
\hline Lower Limit & 395.65 & 9.90 & 0.99 & 0.40 \\
\hline
\end{tabular}

\section{CONCLUSION}

An innovative virtual vacuum gauge controller has been designed and made in the LabVIEW graphical programming environment, where, without a vacuum controller, by a simple scheme, using the Duniway DST-531 sensors and a multifunction I/O device NI6210, is possible pressure measurement in the range $4 \times 10^{2}-4 \times 10^{-1} \mathrm{~Pa}$. In addition, in such virtual vacuum gauge controller, the number of measured parameters depends only on the number of channels of the multifunction I/O device and thus is economically rather profitable.

\section{ACKNOWLEDGMENTS}

This work was supported by Shota Rustaveli National Science Foundation (SRNSF), Grant number: 217524, Project title: Influence of the polymerization and various dopants on the $\mathrm{Hg}-1223$ superconductive properties.

\section{REFERENCES}

[1] Tuwei A.K., Karimi P. M. , Njogu S: Automation of pressure and temperature measurement in vacuum deposition systems, International Journal of Current Research Vol. 5, Issue, 08, August, 2013, pp.21652168 ,

[2] B. Ando', A. Ascia, S. Baglio, N. Pitrone: Experimental Training on Advanced Technologies, Engineering Faculty, D.I.E.E.S. University of Catania, Italy, WSEAS Transactions On Advances In Engineering Education Issue 8, Volume 5, August 2008, pp. 519-528

[3] Debasish Mondal, Dayanidhi Yadav, Ranjeet Kumar, Pankaj Kumar: LabVIEW Based Water Temperature Measurement \& Control, Book, Beliaghata, Kolkata, West Bengal, Maulana Abul Kalam Azad University of Technology, 2018, pp. 36

[4] Xingju Wang, Zongjian Huang: Design of Temperature Measurement and Data Acquisition System Based on Virtual Instrument LabVIEW, TELKOMNIKA Indonesian Journal of Electrical Engineering, Vol. 12, No. 8, August 2014, pp. $6027 \sim 6035$

[5] National Instruments LabVIEW Measurement Manual, National Instruments Corporation, Austin, Texas, July 2000 Edition, pp. 358

[6] LabVIEW for Everyone: Graphical Programming Made Easy and Fun, 3rd Edition Prentice Hall; New Jersey, USA, August 6, 2006, pp.1040 
[7] Behzad Ehsani: Data Acquisition Using LabVIEW Publisher: Packt Publishing, Birmingham, UK, December, 2016, pp.122

[8] I. Metskhvarishvili, T. Lobzhanidze, G. Dgebuadze, B. Bendeliani, M. Metskhvarishvili, V. Gabunia: $\mathrm{HgBa}_{2} \mathrm{Ca}_{2} \mathrm{Cu}_{3} \mathrm{O}_{\mathrm{y}}$ Superconductor Prepared by as Vapour Diffusion Process Chemical Engineering of Polymers Production of Functional and Flexible Materials, Part III: Materials and Properties, Chapter 22. pp. 482

[9] I.R. Metskhvarishvili, G.N. Dgebuadze, B.G.Bendeliani, M.R Metskhvarishvili, T.E. Lobzhanidze, G.N. Mumladze: "Low Field ac Susceptibility and High Harmonics Studies in $\mathrm{PbMo}_{6} \mathrm{~S}_{8}$ Polycrystalline Superconductor", Journal of Low Temperature Physics, Vol. 170 2013, pp. 68-74

[10] Dorothy M. Hoffman, Bawa Singh, John H. Thomas, III: Handbook of vacuum science and technology / ACADEMIC PRESS, San Diego, USA, 1997, pp.86
[11] L.N. Rozanov: Vacuum Technique 1st Edition, CRC Press; UK, April 4, 2002, pp.360

[12] Reál J. Fradette: Understanding Vacuum and Vacuum Measurement, Solar Atmospheres, Inc, USA, 2016. pp.16

[13] Fred Rosebury: Handbook of Electron Tube and Vacuum Techniques, Addison-Wesley Publishing Company, Inc. Reading, Massachusetts, USA, 1993, pp.589

[14] John F. O'Hanlon: A User's Guide to Vacuum Technology, 3rd Edition, Wiley-Interscience; (July 4, 2003), pp.536 